\title{
A future of journalism beyond the objectivity-dialogue divide? : Hybridity in the news of entrepreneurial journalists
}

\section{Ruotsalainen, Juho}

2019-07-31

Ruotsalainen , J , Hujanen , J \& Villi , M 2019 , ' A future of journalism beyond the objectivity-dialogue divide? Hybridity in the news of entrepreneurial journalists ' , Journalism , vol. 22 , no. 9 , 1464884919867216 , pp. 1-19 . https://doi.org/10.1177/1464884919867216

http://hdl.handle.net/10138/312059

https://doi.org/10.1177/1464884919867216

unspecified

acceptedVersion

Downloaded from Helda, University of Helsinki institutional repository.

This is an electronic reprint of the original article.

This reprint may differ from the original in pagination and typographic detail.

Please cite the original version. 


\title{
A future of journalism beyond the objectivity-dialogue divide? Hybridity in the news of entrepreneurial journalists
}

\begin{abstract}
As pioneers of new ideas and practices, many entrepreneurial journalists spearhead the change of journalism towards hybridity. By applying appraisal theory, this article examines a hybrid of objectivity and dialogue in daily news articles by five entrepreneurial journalism outlets - Axios, M ustRead, National Observer, The Skimm and the Voice of San Diego. For comparative purposes, a dataset from three legacy media outlets was also analysed. The results show that the entrepreneurial journalism outlets employ journalistic dialogue in otherwise stylistically objective news texts notably more often than do legacy media outlets. Dialogic registers provide subtle, non-partisan assessments of events and issues and make the news more informal. Such a hybrid form of journalism serves the functions of sense-making, establishing an interpersonal connection between 'private' audiences and 'public' news, and connecting journalism with fields outside of its core. By doing so, the hybrid journalism of entrepreneurial journalists offers a distinctive vision of the futures of news journalism.
\end{abstract}

Keywords: Appraisal theory; Dialogue; Entrepreneurial journalism; Future of journalism; Hybrid journalism; Objectivity

\section{Introduction - entrepreneurial pioneers and journalism's hybrid futures} M yriad possible futures of journalism are being imagined and created in the present by its many pioneers (Hepp \& Loosen, 2018). A prominent pioneer group in journalism are entrepreneurial journalists - journalists who have established their own media outlets and often produce journalism in new ways (Briggs, 2012). Pioneering entrepreneurial journalists can be 'innovation agents' (Carlson \& Usher, 2016), creating not only economic but also new cultural and social value in journalism. By doing journalism differently, they actualise its dormant potentials and open new pathways for its development (Poli, 2010). 
By studying daily news produced by entrepreneurial journalists, this article investigates the emerging futures of journalism - the current ideas, practices, and socio-material conditions that can shape how the future of journalism unfolds and is made sense of. As new forms of journalism combine existing elements and operate in a deeply networked media ecology, they are conceptualised as hybrids. In this article, hybrid journalism is defined as combining the 'competing' journalistic ideals and practices of objectivity and dialogue (Soffer, 2009). The article argues that the ideal and practice of objectivity are becoming somewhat unfit in the digital media ecology, whereas dialogue arguably reflects by nature the affordances, needs and values of the digital, social platform era. Rather than actual conversations, journalistic dialogue is understood in the Bakhtinian (1981) sense as a textual-stylistic feature of subjectivity, intersubjectivity, and polyphonic registers in news texts. Daily news is a fertile site for the study of hybridity because 'hard news' has traditionally adhered strictly to the objectivity norm and neglected dialogue (Raeijmaekers \& Maeseele, 2017; Soffer, 2009).

Hybrid journalism is a constituent of a broader hybrid media system where different values, technologies, practices and actors are enmeshed and mutually influential (Chadwick, 2013). The concept of hybridity situates journalism within dense actor networks or assemblages in which numerous actors affect each other and the ontological focus is on the connections between different actors, fields and phenomena (Chadwick, 2013: 63; Witschge et al., 2019). As hybridity describes the particular dynamics through which the present and future of journalism are made sense of, the concept itself is an anticipatory one. Hybridity depicts the development of journalism towards a networked, de-bounded and de-institutionalised future where the norm of objectivity nonetheless continues to function at the centre of professional journalism (Deuze $\&$ Witschge, 2018; Loosen, 2015).

According to Splichal (2018), the interconnective nature of the internet creates hybrids of the private and the public. This is exemplified in how digital (public) news streams are blended with audiences' personal and affective reactions to them (Papacharissi, 2015). The increasingly symbiotic and intimate relationship between digital journalism and audiences (Steensen et al., 2019) arguably applies specifically to entrepreneurial journalism and sets it apart from legacy media (e.g. Siapera \& Papadopoulou, 2016). Brouwers (2017) defines entrepreneurial journalism as a process of becoming-with, constructed in its connections with other actors, such as the tech/hacker scene (Usher, 2017) or audience members and communities. Prior research shows 
that entrepreneurial news brands seek to become an organic part of audience communities (Malmelin \& Villi, 2016) by building an intimate relationship with them through the extensive use of social media (Harlow \& Chadha, 2018; Porlezza \& Splendore, 2016). Entrepreneurial journalists develop new communicative registers that express the private subjectivity of a journalist and are deployed to bridge the distance between audience members' private life worlds, the general public and journalists (Harbers, 2016). Entrepreneurial journalists pursue stories in which they are personally interested (Heft \& Dogruel, 2019) and specialise in niche topics rather than serve the general public (Cook \& Sirkkunen, 2013). M any entrepreneurial outlets also practice new forms of public journalism which seek to galvanise digitally enhanced audiences in matters of public interest (Ferrucci, 2017).

\section{Hybridity and the future of news}

\subsection{Hybridity in journalism studies}

The contemporary digital media ecology has developed into what Chadwick (2013) labelled a hybrid media system in which content is collectively produced, distributed and interpreted by journalists, citizens, bloggers, activists and other actors. Hybridity is an anticipatory concept that makes sense of the present in certain ways and orients the field of media towards its futures (Poli, 2010). The farther ahead journalism moves into the digital future, the more profoundly can hybridity be expected to manifest in journalism. Hybridity increasingly shapes journalism not only at the 'peripheries' of journalism, such as blogs or infotainment (Loosen, 2015), but also at its 'core', such as daily news.

Although the concept of hybridity has become established in journalism studies, its implications remain under-explored (Baym, 2017). Studies on hybridity tend to adopt a systemic view (M ellado et al., 2017), analyse hybrid values and conceptions (Ruotsalainen \& Villi, 2018; Vos \& Singer, 2016) or focus on hybrid 'soft news', such as celebrity journalism (Van Den Bulck et al., 2017). Empirical studies on hybrid 'hard news' are scarce (see Bødker, 2017; Hamilton, 2016). Witschge et al. (2019) criticised the concept of hybridity as a shortcut to denoting everything complex in the field of journalism as hybrid. They emphasised the need for journalism studies to describe complexity in non-binary ways instead of just naming fluid phenomena as hybrid, in effect reducing them into binary oppositions, like professional/amateur. As a solution, Witschge et al. (2019) offered a change of perspective from pre-fixed binary concepts to fluctuating situations and interactions within socio-technical networks. Following Latour (1993), hybridity can thus be 
conceived as a feature of socio-technical/material networks through which complex patterns hybrids - are formed and reformed.

One way to situate hybridity in broader contexts and specify it as an anticipatory concept is to look at its socio-technical drivers. At least three such drivers can be identified in literature. First, hybridity is driven by new production and distribution platforms of news (Chadwick, 2013). Platforms bring forth a diverse set of producers with increasingly pluralised voices (Bødker, 2017; Ottovordemgentschenfelde, 2017). The variation that accompanies hybridity can help journalism adapt to the new platforms and the new practices, values and forms of interaction related to them (Mast et al., 2017).

Second, hybridity is driven by journalists' need to connect and cooperate with their audiences. At its core, this need stems from the rise of interest-based networks of audience communities (Malmelin \& Villi, 2016) on social media. Audiences are increasingly choosing content based on personal interest, importance and relevance (Ottovordemgentschenfelde, 2017). By tailoring hybrid news language to specific audiences, journalists seek to establish an emotional and engaged connection with them, to become a part of audiences' peer networks, and to address the interests of niche audiences (Baym, 2017; Bødker, 2017; Witschge et al., 2019).

Third, with hybridity, journalists seek to respond to the perceived limitations of legacy journalism in the digital era. Hybrid norms can allow the challenging of the powerful more boldly than legacy journalism often feels comfortable with (Bødker, 2017; Hamilton, 2016; Hutchby, 2017). Hybridity also covers the linguistic devices with which journalists make sense of events. By infusing journalism with the social, the personal and the literary, hybridity frees journalism from primarily describing the concrete, the particular and the denotative - to explore different connotations, values, relationships and concepts of the increasingly complex socio-political world (Baym, 2017).

\subsection{Hybridity at the intersection of public and private}

While going beyond binary concepts in theorising hybridity is a worthwhile pursuit, such concepts still offer a heuristic with which to make sense of hybridity and the complexity of contemporary journalism (Witschge et al., 2019). The three drivers of hybridity in the previous section describe in different ways how hybridity bridges the private-public binary. The public sphere refers to a reasoned discussion and civic involvement in representative democracy, while the private sphere is a space - physical or virtual - where the potentials of one's being may be freely expressed and 
counter-publics articulated (Papacharissi, 2010: 132).Thus, in the digital, hybrid media system, audiences consume and respond to the (public) news in a private, personal and affective manner: constructing reflexive identities, expressing themselves, and seeking human connection (Kreiss, 2018).

Issues previously deemed as private, such as sexual identity, are increasingly understood as having public relevance (Hanitzsch \& Vos, 2018). Furthermore, audiences are increasingly contributing to the news as sources of revenue and algorithmic insights about audience needs, identities, values and tastes (Anderson, 2011; Lehtisaari et al., 2018). Newsrooms have responded by employing subjective communicative registers that convey the private states of a journalist - opinions, emotions or views - such as writing about a 'tragic accident' instead of just an 'accident' (Welbers \& Opgenhaffen, 2018: 7).

The eroding public-private divide in journalism is shifting the focus from a universal public space to many different public spheres that are not only rational but also affective (Papacharissi, 2015). This change necessitates increased diversity in news media. Fraser (1992) warns that if journalism is to address audiences in a multicultural society, it must be able to speak in the authentic voices of different audiences. M any entrepreneurial news organisations already seek journalists with aesthetic sensibilities which align with the tastes of younger audiences and correspond with personal and emotional news discourses (Stringer, 2018).

Digitally enhanced individuals articulate issues within their personal interests and tastes to be addressed publicly, fostering new political imaginations (Splichal, 2018). Papacharissi (2010: 19, 131) observes how the digitally enabled citizen is developing new civic habits: adopting a personally devised definition of the political, becoming politically emancipated through private reflection and expression, and developing new, affective civic vernaculars that mix private and public registers of communication. In journalism, such civic vernaculars can be found in the hybrids of the ideal and practices of journalistic objectivity and dialogue.

\subsection{Hybrid journalism as the mixing of dialogue and objectivity}

Within journalism, hybridity can be understood as the blending of the 'competing' journalistic ideals of dialogue and objectivity (Soffer, 2009). These two ideals have traditionally been regarded as mutually exclusive because they belong to distinct journalistic cultures with differing views about the epistemology, reporting styles and functions of journalism (Soffer, 2009). However, the 
distinction is beginning to blur. Hornmoen and Steensen (2014) note that digital journalism blends objectivity with emerging dialogical relationships, such as between text and audiences, journalist and audiences, and text and other texts. This is especially due to the blurring of borders between the public and private spheres in digital networks (Hornmoen \& Steensen, 2014). In digital networks and related publics, the ideal often is the personal, authentic and private connections between individuals (Papacharissi, 2010). Dialogue fosters personal connections between texts, journalists and audiences (Hornmoen \& Steensen, 2014), whereas objectivity belongs more to the impersonal public world (Kunelius, 2001).

The ideal of objectivity is to provide a balanced and impartial public presentation of the world - to ensure that different interests in society are covered equally (Raeijmaekers $\&$ M aeseele, 2017). An 'objective' reporter is seen as mediating a factual, single public reality on the basis of impartial observation and gathering of facts (Soffer, 2009). Fact-based reporting is believed to foster a truthful social and political consensus (Raeijmaekers \& M aeseele, 2017). The dialogic ideal, in turn, is to present a pluralist polyphony of views of the world, encourage different interpretations instead of a unified message, stimulate non-consensual public discourse and inspire a communal political life (Soffer, 2009). Dialogic journalism speaks from an 'I-thou' relationship between private, subjective persons (Hornmoen \& Steensen, 2014). A dialogic production of knowledge is a constantly evolving and interactive process including an independent assessment of issues and expert claims by journalists (M archionni, 2014; Soffer, 2009). From a dialogic perspective, journalism is not seen as the mere transmission of information but as a ritualistic coming together, a creation and maintenance of meaningful cultural worlds and shared interpersonal meanings within society (Carey, 1992).

An 'objective' style refers to a distanced and impersonal voice describing facts and presenting supporting evidence including quotes from expert sources (Tuchman, 1972). The form of 'objective' news is structured in the inverted pyramid formula (Tuchman, 1972), which is aimed at providing exact information in a concise manner (Chalaby, 1996). By contrast, in terms of style, dialogic news texts are characterised by polyphonic registers (intertextuality) and an informal, conversational tone reflecting the interpersonality between journalists and audiences (Bakhtin, 1981; Hornmoen \& Steensen, 2014). The purpose of a dialogic style is to make the tone of journalism more accessible, varied, and entangled with the aesthetic and intellectual tastes of private individuals (Marchionni, 2014). This is reflected in the form of dialogic journalism, which is 
structured around the interpretations and impressions of a journalist rather than the formal inverted pyramid (Chalaby, 1996).

Despite its status as a foundational premise of journalism (St. John \& Johnson, 2012), objectivity was born in a specific historical context to fulfil specific functions. First, the objectivity norm emerged as part of the professionalisation of journalism in the first half of the $20^{\text {th }}$ century. It legitimised journalism as a distinct and respected occupation in an era where science and industrial efficiency were valorised against the partisan 'tribality' of the $19^{\text {th }}$ century (Schudson, 2001: 162). Second, the norm of objectivity was motivated by a change in business models from subscriptions to advertising: detached objectivity provided an appropriate style of presenting news to a mass audience, which the ad model required (St. John \& Johnson, 2012). Third, technology played a part. Carey (1992) argues that the telegraph freed communication from geographic proximity and encouraged a concise and standardised language that transmits information independent of any interpersonal relationship between the sender and receiver. Finally, 'objective' journalism and its rational and empirical ideals were part of the institutional structure of the liberal democratic market society and its reasoned, expert-led public discussion (Broersma, 2007).

What will happen to objectivity now that all its historical preconditions are undergoing fundamental changes? The positivist industrial approach and reliance on experts do not suffice to legitimise journalism (Broersma, 2007); business models are changing back to subscriptions and pay models, encouraging a focus on niche audiences (Lehtisaari et al., 2018); the public sphere has been hugely diversified by the spread of the internet (Dahlberg, 2007); and the liberal, consensusbased democracy is becoming increasingly fragmented and polarised (Davies, 2018). In this context, adhering strictly to the norms and practices of objectivity can prove increasingly counterproductive. According to Waisbord (2019), the professional ideals of traditional journalism seek to reinforce boundaries, whereas blurred boundaries are intrinsic to digital journalism. Practising a strict form of boundary-drawing objectivity (Schudson, 2001) could leave journalism isolated from its audiences in an increasingly connected world. Furthermore, as Raeijmaekers and M aeseele (2017) argue, rather than reflecting the increasingly pluralistic voices in society, objectivity restrains journalism to being 'balanced' and 'impartial', within the limits of existing institutional politics and its communicative registers - in effect, excluding a wide range of voices, ideas and ideological positions. 
All of these shifts challenge what objectivity is and should be, but do not necessarily make it obsolete. It is difficult to imagine professional journalism without any notion and ideal of objectivity (M cNair, 2017). Provided that 'objectivity' still forms the basis for trust in journalism, M cNair (2017) suggests more modest claims to truth, transparency about journalistic choices and an increasingly critical stance towards authoritative sources as a way forward for the ideal and practice of objectivity. According to Raeijmaekers and Maeseele (2017), in turn, the future practice of objectivity should benchmark ideological contestation rather than support social and political consensus. This type of professional journalism is presently practiced by a few rare pioneers, such as Vice Media's hybridisation of alternative and legacy journalism (Hamilton, 2016).

Hybridising objectivity with journalistic dialogue could facilitate realising the above suggestions and adapt objectivity to contemporary contexts. As the ideal of dialogue does not call for detachment, drawing from dialogue could help journalists adopt a more independent and critical position towards sources. Practising journalistic dialogue alongside 'objectivity' can bring to the fore ideological contestation, a plurality of truths and a more nuanced treatment of issues rather than embracing consensus (Hornmoen \& Steensen, 2014). Furthermore, dialogue may provide journalism with new, more diverse communicative registers. If objectivity draws boundaries around journalism, renders its style uniform and standardised, and confines journalism within established institutions, dialogue is by nature attuned to networks and capable of assimilating different expressive registers. Whereas the ideal of objectivity is to abstain from explicitly supporting social relationships other than rational public discussion, dialogue promotes the construction of private and social identities (Kunelius, 2001). It offers audiences a subjectively meaningful, intimate and interpersonal public connection by helping them orient towards intellectual or demographic communities - that is, publics in the plural (Fraser, 1992; Marchionni, 2013).

In practice, a hybrid of objectivity and dialogue could manifest in journalistic articles that seek to deliver facts in an economic manner while incorporating a wider range of voices and deploying diverse communicative registers. Such hybrid articles could be structured in an inverted pyramid and use expert sources, but would make the mediating subjectivity of a journalist present, however subtly. This type of hybrid journalism would retain 'objectivity' as a professional norm, but would help journalism respond to diversifying and fragmenting audiences, politics and social 
relations - possibly re-acclaiming journalistic authority through more modest and diversified claims to truth.

\section{Data and method}

The empirical section of this article presents an analysis of textual dialogue - operationalised as subjective and conversational registers - in entrepreneurial journalism that is otherwise presented in an objective, detached style. Such a form of journalism represents not just a textual hybrid of the ideals of objectivity and dialogue (Soffer, 2009) but also a hybrid of the public and private modes of expression (Papacharissi, 2015).

The main data (128 daily news articles) were collected between the 25th of January and the 14th of $\mathrm{M}$ arch 2018 from five entrepreneurial news media outlets. All daily news articles not labelled as opinion, analysis or commentary were selected until approximately 9,700 words per outlet was reached. The included outlets were Axios (est. 2016; US), M ustRead (est. 2017; Finland), National Observer (est. 2015; Canada), The Skimm (est. 2012; US) and the Voice of San Diego (VoSD) (est. 2005; US). National Observer is a general-interest news site, while the others focus on specific topics or audiences. Axios produces concise news on politics and technology for a target audience of decision-makers in administrations and companies (Nahser, 2018). Similarly, M ustRead's core audience are Finnish decision-makers. VoSD targets the residents of the San Diego region, whereas The Skimm focuses on millennial women.

The outlets were selected based on the criterion that they generated daily news output, as such genres as analysis and commentary were not expected to adhere to the norm of objectivity (and hence were not apt examples of hybrid journalism as defined in this paper). The selected outlets are exceptions in entrepreneurial journalism insofar as entrepreneurial news outlets tend to produce genres other than daily news, such as explanatory journalism (e.g. Vox in the US), investigative journalism (e.g. the Hungarian Direkt36), slow journalism (e.g. the Dutch De Correspondent) or partisan journalism (e.g. The Canary in the UK). As the number of media brands included was rather small and geographically concentrated in North America, generalising from the results should proceed cautiously. However, because entrepreneurial journalists exhibit similar conceptualisations of journalism across geographical divides (Wagemans et al., 2019), the actual journalism they produce should also demonstrate similarities in different parts of the world. 
For comparative purposes, another dataset of 22 randomly selected news articles - approximately 19,200 words in total - were collected from legacy media outlets: Associated Press, Helsingin Sanomat (the largest daily newspaper in Finland) and The New York Times, between the 24th of January and 23th of M arch 2018. These legacy outlets were selected because they are well-known brands with a long history - all of them were established in the nineteenth century - in traditional news journalism adhering to the norm of objectivity. In the presentation of the results, the three legacy outlets are treated as one unit, i.e., without presenting the results separately per outlet. As the legacy media data consist of approximately 19,200 words, the number of coded instances was divided by two when presenting the results in order to approximately correspond to the 9,700word unit of entrepreneurial media brands.

Investigations into dialogue in journalism rarely follow a systematic method. This article employs appraisal theory, which is used to study dialogue, interpersonal meanings and subjectivity in otherwise 'objective' texts (M artin \& White, 2005; Wahl-Jorgensen, 2013). Appraisal theory concerns 'the interpersonal in language, with the subjective presence of writers/speakers in texts' (Martin \& White, 2005: 1). The textual analysis is done by mapping out appreciations, judgements and affect, as well as engagement in texts (Martin \& White, 2005). Such appraisals manifest journalistic dialogue in expressing the subjective 'private state' (Welbers \& Opgenhaffen, 2018: 7) of a journalist and invite the reader to participate in an interpersonal, dialogic relationship with the text. Appraisals activate evaluative and affective stances in audience members, prompting them to supply their own assessments ( $M$ artin \& White, 2005: 2). Reflecting the ideal of dialogue, appraisals express a pluralist polyphony of views and highlight different interpretations instead of a unified, 'objective' message. Through such dialogic stances, appraisals bridge the public and private - that is, public issues are addressed from private, intersubjective positions.

The appraisals by journalists - appraisals not attributed to a source - were coded in the data according to the following definitions:

Appreciation - evaluations of things and issues ('an interesting event')

Judgement - evaluations of human behaviour and character ('a suspicious person')

Affect - descriptions or expressions of emotions ('the President hates')

Engagement - rhetorical passages that engage or converse with alternative viewpoints and voices ('it seems', 'this is not true'). 
In addition to the four appraisal categories, vernacular passages - informal or literary utterances were also coded. Informality, a casual tone and literary registers are core features of dialogue in journalism (M archionni, 2013; Soffer, 2009). They highlight the aspect of dialogue that emphasises a plurality of voices and expressive registers which are oriented towards intellectual, demographic or other communities at the intersection of public and private.

Because the focus of the analysis was on journalistic dialogue, objective news style was not analysed in depth. For the purposes of the article, it suffices to note that the analysed entrepreneurial outlets comply with practices of the objective style of news presentation (Tuchman, 1972): they employ summary leads of the inverted pyramid news structure, quote experts and abstain from expressing partisan opinions.

Identifying and coding appraisals is a complex, time-consuming and, to some extent, interpretive process ( $M$ artin \& White, 2005). To avoid potential biases in the coding process, the unit of coding was (for the most part) one word. An appreciation 'beautiful and nice' would thus be coded as two separate appreciations ('beautiful' and 'nice') instead of one. However, in invoked, implicit appraisals, more than one word was usually coded; as in such cases, their meanings were not as clear-cut as those derived from inscribed, explicit appraisals. Second, the coding was cyclically refined for test-retest reliability and internal consistency. Third, the level of analysis was kept relatively rough to make the coding less complex: only the main categories of each appraisal class were coded. For instance, all the subcategories of judgement (ability, propriety, tenacity) ( $M$ artin $\&$ White, 2005) were coded under judgement without explicating the subcategories. Fourth, for the purposes of systematicity, neutral and descriptive appraisals, such as portraying a financial transaction as 'major', were coded as well.

\section{Connecting with the readers and offering interpretation - the appraisal analysis}

The analysis showed that both the entrepreneurial and legacy outlets use appraisals, but that the entrepreneurial outlets do so more frequently. The most notable difference was in vernacular language: entrepreneurial outlets use it relatively often, while legacy media almost never do. National Observer is an outlier, as it employs all appraisal resources as well as vernacular registers less frequently than even the legacy media do. National Observer has thus been excluded from the qualitative analysis in Sections 4.1, 4.2 and 4.3. 
Table 1 summarises the findings as frequencies of different types of appraisals and vernacular language in the data. As the samples are not representative and no statistical methods were used, the quantitative presentation of the results is merely indicative. Its purpose is to give an overview of the results and to reveal where differences between entrepreneurial and legacy media could be found in larger samples.

The ratios in the rightmost column of Table 1 show that the analysed entrepreneurial media stand apart from the legacy media the most in terms of appreciations, vernacular language and engagement. Regarding engagement, it must be noted that its subcategory attribution (*source* says, according to *source*, etc.) is a standard means of reporting. Entrepreneurial outlets employ a wider range of engagement resources (Table 2). If attributions are excluded, the ratio of engagement is 1 to 3 .

The three categories with the largest discrepancy between legacy and entrepreneurial media appreciations, vernacular language and engagement - were selected for a closer interpretation in the following three sections. The interpretation of the appraisal analysis shows that appreciations and vernacular voices perform the functions of analysis and interpretation, connecting with the readers, and broadening the expressive palette a journalist can draw from. The analysis on engagement shows that the resources of engagement are employed to help the reader navigate the news and connect with audiences. In the quotations under Sections 4.1, 4.2 and 4.3, words or word sequences belonging to a corresponding category are presented in italics.

Table 1. Coded references of appraisal resources and vernacular passages per approximately 9,700 words.

\begin{tabular}{|l|l|l|l|l|l|l|l|l|}
\hline $\begin{array}{l}\text { Type of } \\
\text { appraisal }\end{array}$ & The Skimm & MustRead & VoSD & Axios & $\begin{array}{l}\text { Legacy } \\
\text { media }\end{array}$ & $\begin{array}{l}\text { National } \\
\text { Observer }\end{array}$ & $\begin{array}{l}\text { Entrepreneurial } \\
\text { media avg. } \\
\text { (Excl. National } \\
\text { Observer) }\end{array}$ & $\begin{array}{l}\text { Legacy to } \\
\text { entrepreneurial } \\
\text { media ratio }\end{array}$ \\
\hline Appreciation & 116 & 160 & 79 & 76 & 45 & 21 & 108 & 1 to 2.4 \\
\hline Judgement & 43 & 58 & 26 & 23 & 22 & 4 & 38 & 1 to 1.7 \\
\hline Affect & 31 & 16 & 19 & 11 & 16 & 6 & 19 & 1 to 1.2 \\
\hline
\end{tabular}




\begin{tabular}{|l|l|l|l|l|l|l|l|l|}
\hline Engagement & 642 & 492 & 365 & 318 & 264 & 287 & 454 & $\begin{array}{l}1 \text { to } 1.6 / \\
1 \text { to } 3\end{array}$ \\
\hline $\begin{array}{l}\text { Total } \\
\text { appraisals }\end{array}$ & 832 & 726 & 489 & 428 & 347 & 318 & 619 & 1 to 1.8 \\
\hline $\begin{array}{l}\text { Vernacular } \\
\text { expressions }\end{array}$ & 427 & 38 & 53 & 76 & 6 & 2 & 149 & 1 to 25 \\
\hline
\end{tabular}

\subsection{Appreciations}

Entrepreneurial outlets use appreciations - evaluations of things, issues and phenomena - first and foremost to build an extra layer of contextualised analysis and interpretation in the news. Appreciations describe things not directly perceivable in the news event, but which can be conceived through the journalist's analytical prowess and affective, tacit knowledge. As an example, employer healthcare plans are contextualised as follows: 'Corporate profits have dramatically outpaced wages and health benefits since the turn of the century' (Axios). The reader not only receives factual information about employer healthcare plans but is also informed about broader socio-economic changes. The journalist assesses the changes affectively as dramatic, which invites readers in an imaginary dialogue to evaluate the issue from their own political and moral stances (Martin \& White, 2005) or affective private states (Welbers \& Opgenhaffen, 2018). As an issue of public relevance is signified as subjectively meaningful, the conjured relationship is a public-private hybrid.

Appreciations explain to the reader 'Why it matters' - an evaluative subtitle used by Axios and VoSD. M ustRead, for instance, argues that decreases in national Finnish R\&D funding matter, in part, because they may make it more difficult to obtain funding from the EU: 'Domestic key projects do not weigh much when the EU allocates research funding'. This is in line with Baym's (2017) suggestion that hybrid journalism is suitable for dealing with connotations of current events, whereas traditional news journalism is more comfortable with the denotative and the concrete. The connotative approach can potentially foster a political imagination and give rise to nascent political ideas within the private sphere and its different groups (Kunelius, 2001). In line with the ideal of dialogue, appreciations underline polyphonic views and interpretations of the truth. Appreciations reveal 'hidden' sides of a story, drawing attention to the complex nature of 
issues and processes. Such assessments can be marked explicitly with subtitles such as 'Reality check', 'Yes, but' or 'Tell me more' (Axios, The Skimm). The passages following these kinds of subtitles offer extra information that sheds light on the different details, viewpoints and complexities regarding the issues at hand.

The use of appreciations to interpret and explain can be labelled as sense-making: journalists' prior knowledge and re-procession of information - their entire mediating subjectivity (Chalaby, 1996) - provides readers with something 'extra' to help them make sense of the world. For instance, when a journalist portrays text messages between FBI agents as 'genuinely troubling' (Axios), the journalist is questioning a presumably common view that the FBI is a neutral organisation to be trusted while simultaneously pointing out that the text messages will likely be taken as further evidence of 'a Deep State coup' by the conservative right.

In accordance with the ideal of objectivity, appreciations employ the mediating subjectivity of the journalist for analytical, not opinionated, purposes. Intersubjective appreciations establish a public-private hybrid connection between audiences, journalists, events and issues. This potentially helps audience members not only understand the world more comprehensively but also make sense of themselves, seek human connection and construct reflexive identities as part of the socio-political world that they inhabit.

\subsection{Vernacular language}

Like appreciations, vernacular language - informal registers, the first and second person pronouns, and literary styles - is used as a vehicle for interpretation and sense-making. News is not presented as a neutral transmission from the outside world, but rather as explicitly processed and addressed through the mediating subjectivity of the journalist, by her or his knowledge and impressions of current affairs. The significance of a political decision can be emphasised, for instance, by calling it a 'big deal' (The Skimm). As another example, when a journalist ironically states that 'Finnish municipalities are not necessarily known for their willingness to cooperate' (M ustRead), he reveals tacit, contextualising 'backstage' knowledge about Finnish municipalities.

The dialogic and private features are perhaps the most explicitly present in vernacular textual devices. The Skimm explains on its 'About Us' page that its goal is to integrate in 'the routines of our target audience - female millennials'. M imicking the vernacular language of an audience segment is one way to do so. A vernacular style presents the news with a laid-back, welcoming 
feel. It lends the outlets a distinct personality and gives an impression of a direct, intimate and private connection with the reader. The use of expressions such as 'screwed up' (Axios) or 'speaking of' (VOSD) gives the impression that the journalist and the putative reader not only share manners of speaking but are almost having a friendly and involved face-to-face conversation. Thus, expressive vernacular language potentially helps in building value-related and aesthetically co-oriented relationships with audiences.

An imaginary, direct conversation with the audience can be made explicit by the use of the first and second person pronouns. Readers can be addressed in the second person: 'Be smart: This strategy [of Trump] is working better than you think' (Axios). Articles can even be structured in the form of a conversation: an imagined reader poses questions as subtitles (e.g. 'What's happening?') or interrupts ('Wait, back up') (The Skimm). The body text of the article then 'responds' to these questions. With the use of the first person, the journalists can make their subjectivity present in a news text, such as stating 'we'd love [to ask a politician some questions]' (VoSD). By writing in the first person, reporters come across as subjective human beings who are present in the news article as conversants, passionate about their jobs and open about where they stand on and how they perceive the world.

Besides informal and personalised language, conversational registers also incorporate literary and narrative styles. Such registers are used to convey connotative impressions from the news scene and about current politics, with an assumed goal of making them seem more alive and 'real', like in the following eloquent description of the upbeat feeling of the audience in a municipal meeting: "'Resist", she said, as applause filled the night air' (VOSD). M etaphors and idioms can also offer concise and holistic interpretations of issues, such as describing the current politics in the US as a 'great disorientation machine' (Axios).

\subsection{Engagement}

Textual engagement places a text in a dialogic relationship with participants in an imaginary discussion. The writer can engage in an imaginary dialogue by either expanding or contracting possible meanings and interpretations. Dialogic expansion refers to a writer/speaker who allows and introduces alternative positions. This can take the form of entertaining speculative possibilities (perhaps, may be, it seems) or attributing external voices ( $X$ says, many believe, the report states). Dialogic contraction, in turn, means challenging, fending off or restricting other 
views. It is expressed in disclaims (denials, counter arguments) or proclaims (concurring, pronouncing or endorsing certain viewpoints). (M artin \& White, 2005.)

The analysed entrepreneurial media outlets engage in this kind of textual dialogue more extensively than do their counterparts in legacy media. Entrepreneurial media outlets in the data both contract and expand meanings more often than do the legacy organisations (Table 2). $M$ anifesting the ideal of journalistic dialogue, this suggests that the entrepreneurial outlets see their message not as simple objective facts to be received and accepted by audiences, but as information that remains open to discussion, promotion, counter-arguments and polyphonic contributions. As with appreciations and vernacular language, the resources of engagement perform a sense-making function in the presentation of the news. These features promise to make the news more understandable, contextualised and closer to the private life spheres of audiences.

Table 2. Coded references of engagement per approximately 9,700 words.

\begin{tabular}{|l|l|l|l|l|l|l|l|}
\hline $\begin{array}{l}\text { Type of } \\
\text { engagement }\end{array}$ & $\begin{array}{l}\text { The } \\
\text { Skimm }\end{array}$ & MustRead & VoSD & Axios & $\begin{array}{l}\text { National } \\
\text { Observer }\end{array}$ & $\begin{array}{l}\text { Legacy } \\
\text { media }\end{array}$ & $\begin{array}{l}\text { Entrepreneurial } \\
\text { media average } \\
\text { (excl. National } \\
\text { Observer) }\end{array}$ \\
\hline $\begin{array}{l}\text { Disclaim } \\
\text { (contract) }\end{array}$ & 39 & 56 & 47 & 31 & 12 & $\mathbf{2 1}$ & $\mathbf{4 3}$ \\
\hline $\begin{array}{l}\text { Proclaim } \\
\text { (contract) }\end{array}$ & 101 & 65 & 30 & 71 & 2 & $\mathbf{1 5}$ & $\mathbf{6 7}$ \\
\hline $\begin{array}{l}\text { Entertain } \\
\text { (expand) }\end{array}$ & 100 & 130 & 72 & 41 & 31 & $\mathbf{2 7}$ & $\mathbf{8 6}$ \\
\hline $\begin{array}{l}\text { Attribute } \\
\text { (expand) }\end{array}$ & 402 & 241 & 216 & 175 & 242 & $\mathbf{2 0 1}$ & $\mathbf{2 5 9}$ \\
\hline & 642 & 492 & 365 & 318 & 287 & $\mathbf{2 6 4}$ & $\mathbf{4 5 4}$ \\
\hline Total & 140 & 121 & 77 & 102 & 14 & $\mathbf{3 6}$ & $\mathbf{1 1 0}$ \\
\hline Contract total & 502 & 371 & 288 & 216 & 273 & $\mathbf{2 2 8}$ & $\mathbf{3 4 4}$ \\
\hline Expand total & & & & & & & \\
\hline
\end{tabular}


In the case of dialogic contraction, the use of disclaims and proclaims can help the reader navigate the news by pointing out what a journalist sees as especially important in an issue. In many cases, the outlets' disclaims or proclaims present the journalist as having greater expertise than the reader. This positions the journalist as a 'guide' for the reader (M artin \& White, 2005: 120), such as instructing a reader to 'Forget the [Republican] memo' (Axios). By proclaiming what aspects and interpretations of an issue matter the most, the outlets reject other possibilities, thus contracting interpretations. Disclaims, in turn, not only ward off opposing stances but can provide counterarguments in an imaginary discussion: 'Even a great year of investment gains doesn't solve the problem [of pension bills], because there is less money to reap the rewards when they come' (VoSD). Such arguments converse with imaginary opponents. They can aid the reader in understanding the news better by considering possible counter-arguments beforehand. Both proclaims and disclaims also build rapport with a putative reader (M artin \& White, 2005: 129-130). When The Skimm, for instance, pronounces its support for a new legislation in France against gender pay gaps in companies by proclaiming 'oui, oui' to the legislation, it assumedly seeks to align with its core audience of millennial women. By building solidarity with a particular group in an informal manner, The Skimm operates in a zone between private and public.

Regarding dialogic expansion, with attributions through hyperlinks, the outlets direct the reader to outside sources for a fuller and broader understanding. By entertaining different possibilities - like rhetorically asking 'what should be the long-term vision [of the Finnish agriculture policy]?' (MustRead) - the outlets help clarify different potentials in the present and expand the time horizon of a news article into the future. That the entrepreneurial outlets entertain different possibilities three times as often as the legacy outlets do (see Table 2) suggests their readiness to expand the news into a speculative arena, possibly helping the audience to better grasp the context of the news and broaden the political horizon outside of the present consensus.

\section{Conclusion}

By applying appraisal analysis (M artin \& White, 2005), this article has shown how news delivery in the studied entrepreneurial journalism cases is stylistically dialogic. The examined outlets use dialogic appraisals and vernacular expressions in daily news notably more often than do the analysed legacy media brands. They can appraise text messages between FBI agents as 'troubling', use informal expressions such as 'screwed up', address readers directly in the second person ('be smart') or position the news text in an imaginary dialogue consisting of arguments and 
counterarguments ('[this] doesn't solve the problem').

As the news of the entrepreneurial journalism outlets is otherwise objective in terms of presentation - they use summary leads, build reporting around expert sources and avoid partisan opinions - their news prose can be described as a hybrid of objectivity and dialogue, the two core ideals of journalism (Soffer, 2009). The identified dialogic style highlights the presence of the journalist's private personality in news texts (Welbers \& Opgenhaffen, 2018), lends an accessible tone to the texts and co-orients with the aesthetic and intellectual tastes of audiences. At the same time, 'objective' textual practices ensure the efficient delivery of verified information and make the news outlets stand apart from, for example, bloggers.

The dialogue- objectivity hybrid is present in how entrepreneurial news brands include both public and private modes of expression in their news. They address issues of public interest and transmit seemingly neutral information, but they do so in a style akin to how people converse in private settings: in an informal, affective and evaluative manner. By delivering the news in vernacular, private voices that mimic the audience's manner of speech, the analysed entrepreneurial media acknowledge public spheres in the plural and bridge the public-private divide. Considering the core audiences of these outlets, their journalism seems to be aimed at engaging, first and foremost, individuals and niche groups instead of a general public: Axios and M ustRead address decision-makers and those with a pronounced interest in politics; The Skimm focuses on millennial women; and VoSD targets residents of the San Diego area. By contrast, National Observer, the only outlet that does not incorporate dialogic and vernacular elements in its reporting, addresses the general public instead of a specific audience segment.

The dialogue in the analysed hybrid news language arguably has two core functions. The first concerns how the world is represented by journalists and highlights their interpretive sensemaking. The evaluative and dialogic style emphasises varied views instead of a unified, 'objective' message. Dialogue can be seen as an attempt to make sense of the increasingly connected, pluralist and complex world, something that mere reporting might be inadequately equipped to do. Appraisals shed light on different connotations of news events and, thus, promise a more comprehensive and deeper view of issues and events. They mobilise a journalist's tacit knowledge about issues, which potentially aids readers to understand the news' broader context. Appraisals can also guide the reader to aspects of a story that the journalist sees as especially relevant, offer 
a broadened view on issues through attributions such as external hyperlinks and make the reader aware of the different potentials in an issue (something 'may happen', for instance). Vernacular language particularly allows a broader set of expressions than permitted by traditional style conventions and can make the meaning of the news resonate with readers on a personal level.

The second function of dialogue concerns building interpersonal relationships with audiences. This function also has a sense-making purpose. The outlets' dialogic style builds the news as an intersubjectively shared, expressive, affective and discursive space that can enhance comprehension and interest and foster a rapport between audiences and journalists. Dialogic resources present the news as a part of an imaginary discussion and seek to build solidarity with readers. Vernacular language reveals some of the identity of the person behind the news, emphasising personal characteristics that audiences may potentially see as desirable and relatable, such as passion, wit and knowing.

A third, more speculative function can be added to the above two. This function constructs and subscribes to a future of journalism that is deeply networked and situational. Dialogue can promote the synching of journalism with the networked digital media ecology and its collaborative post-industrial news (Deuze, 2017). Witschge et al. (2019) conceive of hybridity as a complex, nonbinary relationship between materialities, feelings, professional norms, aesthetic experiences and other such phenomena. New forms of journalism can build on a polyphonic dialogue to expand beyond the newsroom and open up to the world, thereby overcoming binaries, such as the private-public divide. Whereas the objectivity norm confines journalism to strict practices (Tuchman, 1972), dialogue entails a relational ontology of journalism (see Chadwick, 2013; Latour, 1993). According to such a view, journalism eschews a priori definitions and is constantly redefined in particular socio-material contexts, in dialogues between different fields, actors and institutions. Such assemblages can pertain to audiences' communities of interest, journalists' collaborations with NGOs, meshes of journalism and theatre (as in live journalism) or journalistic experiments with virtual reality. While dialogue can enhance the capabilities of journalism to network, the practice and ideal of objectivity can perhaps paradoxically prove increasingly essential in a world of blurred boundaries by providing the existential basis of professional journalism. 


\section{References}

Anderson CW (2011) Deliberative, Agonistic, and Algorithmic Audiences: Journalism's Vision of its Public in an Age of Audience Transparency. International Journal of Communication 5: 529547.

Bakhtin M M (1981) The Dialogic Imagination. Four Essays. Austin: University of Texas Press.

Baym G (2017) Journalism and the hybrid condition: Long-form television drama at the intersections of news and narrative. Journalism 18(1): 11-26.

Bødker H (2017) Vice M edia Inc.: Youth, lifestyle - And news. Journalism 18(1): 27-43.

Briggs M (2012) Entrepreneurial Journalism. How to Build What's Next for News. London: Sage.

Broersma M (2007) Form, style and journalistic strategies. In Broersma M (ed) Form and Style in Journalism. European Newspapers and the Representation of News 1880-2005. Leuven: Peeters, pp. ix-xxix.

Brouwers AD (2017) Failure and understanding within entrepreneurial journalism. Journal of Media Business Studies 14(3): 217-233.

Carey JW (1992) Communication as Culture. Essays on M edia and Society. New York: Routledge.

Carlson M and Usher N (2016) News Startups as Agents of Innovation: For-profit digital news startup manifestos as metajournalistic discourse. Digital Journalism 4(5): 563-581.

Chadwick A (2013) The Hybrid M edia System: Politics and Power. New York: Oxford University Press.

Chalaby JK (1996) Journalism as an Anglo-American Invention. European Journal of Communication 11(3): 303-326.

Dahlberg L (2007) Rethinking the fragmentation of the cyberpublic: from consensus to contestation. New Media \& Society 9(5): 827-847.

Davies W (2018) Nervous States. How Feeling Took Over the World. London: Jonathan Cape.

Deuze M (2017) Considering a possible future for Digital Journalism. M editerranean Journal of Communication 8(1): 9-18. 
Deuze M and Witschge T (2018) Beyond journalism: Theorizing the transformation of journalism. Journalism 19(2): 165-181.

Fraser N (1992) Rethinking the public sphere: A contribution to the critique of actually existing democracy. In Calhoun C (ed.) Habermas and the Public Sphere. Cambridge: The M IT Press, pp. 110-142.

Habermas J (1989 [1962]). The Structural Transformation of the Public Sphere: An Inquiry into a Category of Bourgeois Society. M assachusetts: The M IT Press.

Hamilton JF (2016) Hybrid News Practices. In: Witschge T, Anderson CW, Domingo, D and et al. (eds) The Sage Handbook of Digital Journalism. London: Sage, pp. 164-178.

Hanitzsch T and Vos TP (2018) Journalism beyond democracy: A new look into journalistic roles in political and everyday life. Journalism 19(2): 146- 164.

Harbers F (2016) Time to Engage. Digital Journalism 4(4): 494-511

Harlow S and Chadha M (2018) Looking for community in community news: An examination of public-spirited content in online local news sites. Journalism: 1-20.

Hepp A and Loosen W (2018) 'M akers' of a future journalism? The role of 'pioneer journalists' and 'pioneer communities' in transforming journalism. Communicative Figurations Working Paper no. 19. University of Bremen.

Hornmoen H and Steensen S (2014) Dialogue as a Journalistic Ideal. Journalism Studies 15(5): 543554.

Hutchby I (2017) Hybridisation, personalisation and tribuneship in the political interview. Journalism 18(1): 101-118.

Kreiss D (2018) The Networked Self in the Age of Identity Fundamentalism. In: Papacharissi Z (ed) A Networked Self: Platforms, Stories, Connections. New York: Routledge, pp. 12-28.

Kunelius R (2001) Conversation: a metaphor and a method for better journalism? Journalism Studies 2(1): 31-54.

Latour B (1993) We Have Never Been M odern. Cambridge, Massachusetts: Harvard University Press. 
Lehtisaari K, Villi M , Grönlund M, Lindén CG and et al (2018) Comparing Innovation and Social Media Strategies in Scandinavian and US Newspapers. Digital Journalism 6(8): 1029-1040.

Loosen W (2015) The notion of the "blurring boundaries": Journalism as a (de-)differentiated phenomenon. Digital Journalism 3(1): 68-84.

Malmelin N \& Villi M (2016) Audience Community as a Strategic Resource in Media Work. Journalism Practice 10(5): 589-607.

Marchionni DM (2013) Journalism-as-a-Conversation: A Concept Explication. Communication Theory 23(2): 131-147.

M artin JR and White PRR (2005) The Language of Evaluation. Appraisals in English. New York: Palgrave Macmillan.

Mast J, Coesemans R and Temmerman M (2017) Hybridity and the news: Blending genres and interaction patterns in new forms of journalism. Journalism 18(1): 3-10.

M cNair B (2017) After Objectivity? Journalism Studies 18(10): 1318-1333

M ellado C, Hellmueller L, Márquez-Ramírez M and et al (2017) The Hybridization of Journalistic Cultures: A Comparative Study of Journalistic Role Performance. Journal of Communication 67(6): 944-967.

Nahser F (2018) Email is the product: Insights from Axios, theSkimm, and Quartz.

https://medium.com/global-editors-network/email-is-the-product-insights-from-axiostheskimm-and-quartz-247d8c2b36a2. Accessed 8 ${ }^{\text {th }}$ October 2018.

Ottovordemgentschenfelde S (2017) Organizational, professional, personal: An exploratory study of political journalists and their hybrid brand on Twitter. Journalism 18(1): 64-80.

Papacharissi Z (2010) A Private Sphere. Democracy in a Digital Age. Cambridge: Polity Press.

Papacharissi Z (2015) Toward New Journalism(s): Affective news, hybridity, and liminal spaces. Journalism Studies 16(1): 27-40.

Poli R (2010) The many aspects of anticipation. Foresight 12(3): 7-17.

Porlezza C and Splendore S (2016) Accountability and transparency of entrepreneurial journalism. Journalism Practice 10(2): 196-216. 
Raeijmaekers D and Maeseele P (2017) In objectivity we trust? Pluralism, consensus, and ideology in journalism studies. Journalism 18(6): 647-666.

Ruotsalainen, J. \& Villi, M . (2018). Hybrid Engagement: Discourses and Scenarios of Entrepreneurial Journalism. M edia \& Communication, 6(4): 79-90.

Schudson M (2001) The objectivity norm in American journalism. Journalism 2(2): 149-170.

Siapera E and Papadopoulou L (2016) Entrepreneurialism or cooperativism? An exploration of cooperative journalistic enterprises. Journalism Practice 10(2): 178-195.

Splichal S (2018) Publicness- privateness: the liquefaction of "the Great Dichotomy". Javnost - The Public: 1-10, doi:10.1080/13183222.2018.1424004

Soffer 0 (2009) The competing ideals of objectivity and dialogue in American journalism. Journalism 10(4): 473-491.

St. John B and Johnson KA (2012) Introduction: challenges for journalism in a post-objective age. In: St. John B and Johnson KA (eds) News with a View: Essays on the Eclipse of Objectivity in Modern Journalism. Jefferson, North Carolina: M cFarland \& Company, pp. 1-8.

Steensen S, Grøndahl Larsen AM , Benestad Hågvar Y, and Kjos Fonn B (2019) What does digital journalism studies look like? Digital Journalism 7(3): 320-342.

Stringer P (2018) Finding a place in the journalistic field. Journalism Studies, 1-10. doi:10.1080/1461670x.2018.1496027.

Tuchman G (1972) Objectivity as strategic ritual: an examination of newsmen's notions of objectivity. American Journal of Sociology, 77(4): 660-679.

Usher N (2017) Venture-backed News Startups and the Field of Journalism: Challenges, changes, and consistencies. Digital Journalism 5(9): 1116-1133.

Van Den Bulck H, Paulussen S and Bels A (2017) Celebrity news as hybrid journalism: An assessment of celebrity coverage in Flemish newspapers and magazines. Journalism 18(1): 44-63.

Vos TP and Singer JB (2016) M edia discourse about entrepreneurial journalism. Journalism Practice 10(2): 143-159. 
Wagemans A, Witschge T, and Harbers F (2019) Impact as driving force of journalistic and social change. Journalism 20(4): 552-567.

Wahl-jorgensen K (2013) Subjectivity and story-telling in journalism: Examining expressions of affect, judgement and appreciation in Pulitzer Prize-winning stories. Journalism Studies 14(3): 305-320.

Waisbord S (2019) The 5Ws and 1H of digital journalism. Digital Journalism 7(3): 351-358.

Welbers K and Opgenhaffen M (2018) Presenting News on Social M edia. Digital Journalism: 1-18.

Witschge T, Anderson C, Domingo D and Hermida A (2019) Dealing with the mess (we made): Unraveling hybridity, normativity, and complexity in journalism studies. Journalism 20(5): 651-659. 